\title{
Evaluation of Four-Hand Reduction for Obturator Hernia with The Guidance of Sonography (FROGS) as a New Treatment Strategy for Obturator Hernia: A Retrospective Study
}

\author{
Yuki Togawa ( $\sim$ annemarie1911@icloud.com ) \\ Department of General Surgery, Kurashiki Central Hospital \\ Kyohei Kamihata \\ Department of General Surgery, Kurashiki Central Hospital \\ Yoshio Nagahisa \\ Department of General Surgery, Kurashiki Central Hospital \\ Kazuyuki Kawamoto \\ Department of General Surgery, Kurashiki Central Hospital
}

\section{Research article}

Keywords: obturator hernia, FROGS, reduction, intestinal obstruction

Posted Date: August 23rd, 2021

DOI: https://doi.org/10.21203/rs.3.rs-447904/v2

License: (c) (i) This work is licensed under a Creative Commons Attribution 4.0 International License. Read Full License 


\section{Abstract \\ Background}

Obturator hernias are uncommon but are important causes of intestinal obstruction. Delayed treatment can be fatal. Emergency surgery is considered the most effective treatment; however, patients with obturator hernia usually have comorbidities, and this precludes them from emergency surgery. Previously, a few case studies reported successful manual reductions for an incarcerated obturator hernia. However, their efficacy was not statistically confirmed. We have devised a new manual reduction method for an incarcerated obturator hernia based on previous studies. We have named this method "Four-hand Reduction for Obturator hernia with the Guidance of Sonography" (FROGS). This study aimed to evaluate the effectiveness of FROGS as a new treatment strategy for obturator hernia.

\section{Methods}

Since November 2019, we have tried FROGS in all patients with obturator hernia at the emergency room. We retrospectively compared the clinical data of 14 patients who underwent FROGS (after-FROGS group) with those of 23 patients who did not (before-FROGS group).

\section{Results}

All patients were females. There were no significant differences in age, lesion side, duration of symptoms, the diameter of the prolapsed bowel, and predisposing factors. The body mass index was significantly lower in the after-FROGS group than in the before-FROGS group. Manual reduction was successfully performed in all 14 patients in the FROGS group, whereas in the before-FROGS group, 14 patients underwent manual reduction, of whom only one was successfully treated using the non-FROGS method. Bowel resection was avoided in all 14 patients in the after-FROGS group, whereas 8 patients underwent bowel resection in the before-FROGS group. There were no significant differences in postoperative complications and mortality within 30 days after hernia presentation between the two groups.

\section{Conclusion}

Manual reduction using the FROGS technique was found to be safe and reproducible and can be the first treatment choice for patients with obturator hernia.

\section{Introduction}

Obturator hernias are rare forms of abdominal hernias that account for $<1 \%$ of all abdominal hernias [1]. Although arriving at a definite preoperative diagnosis was difficult in previous years, it has become easy following the use of advanced imaging techniques [2-5]. Obturator hernia usually develops in elderly, thin, and multiparous women who often have comorbidities and other debilitating conditions, and this can preclude them from emergency surgery; therefore, the postoperative mortality rate after emergency surgery is high [6, 7]. However, once diagnosed, emergency surgery is usually performed because delayed treatment can lead to intestinal ischemia and subsequently perforation [1]. Previously, some reports have described successful manual reductions of obturator hernias [8-11]. However, these are case reports and the efficacy of manual reduction is not statistically confirmed. Therefore, there is no controversy about whether manual reduction (with or without elective surgery) or emergency surgery is more effective. Four-hand Reduction for Obturator hernia with the Guidance of Sonography (FROGS) is a simple technique that we devised based on previous reports to treat obturator hernias in the emergency room. This study was performed to evaluate the effectiveness of FROGS as a new treatment strategy for obturator hernias. To our knowledge, this is the first report that examined the effectiveness of manual reduction of obturator hernia based on a statistical analysis.

\section{Methods Study design}

The clinical data of all patients with obturator hernia who were admitted to the Department of Surgery at Kurashiki Central Hospital between April 2016 and September 2020 were retrospectively reviewed. We implemented FROGS in the emergency room as the first choice of treatment since November 2019 . We compared the clinical data (age, sex, body mass index, site of the hernia, predisposing factors, type of surgery, hernia size, complications, hospital stay, outcome, and follow-up) of patients who underwent FROGS (after-FROGS group) with those of patients who did not (before-FROGS group).

\section{Steps of FROGS}

FROGS is a bed-side reduction method in the emergency room that we devised for obturator hernias under real-time sonographic guidance based on previous reports [8-11]. This technique requires two surgeons, which is why it is a "four-hand" technique. Before initiating this procedure, the presence of an obturator hernia (an hernial sac between the adductor longus and the pubis) has to be confirmed. While the surgeon confirms the hernial sac, the assistant supports the patient to keep the hip joint flexed and rotated externally so that the hernial sac can be visualized (Fig. 1).

\section{Step 1}

The surgeon places the transducer in the left hand on the patient's groin area (just cranial to the inguinal ligament) while the right hand pushes the hernial sac. Meanwhile, the assistant places the hip and knee joints in the flexed position. 


\section{Step 2}

The assistant slightly rotates the hip joint laterally, thereby widely opening the hernia orifice (Fig. 2).

\section{Step 3}

The assistant extends the hip and knee joints (Fig. 3).

To facilitate these movements, the assistant places one hand on the patient's upper thigh and the other on the patient's lower thigh. While the assistant performs the three-step maneuver, the surgeon keeps pushing the hernial sac. In Step 3, the surgeon pushes it even harder. The muscles along the obturator canal relax so that the hernial sac can be reduced. Two people continue this maneuver repeatedly until the hernial sac is completely pushed back. This movement may be reminiscent of a frog moving its legs while swimming, which is another reason the method is called "FROGS."

\section{Statistical analyses}

All statistical analyses were performed using R version 4.0.3 software (The R Project for Statistical Computing, Vienna, Austria). Continuous variables are expressed as mean \pm standard deviation, and categorical variables are expressed as absolute numbers and percentages. All variables were analyzed using Student's t-test for continuous variables and the $\chi 2$ test or Fisher's exact test for categorical variables. A p-value of $<0.05$ was considered statistically significant.

\section{Results}

A total of 37 patients with obturator hernias were admitted to the Department of Surgery at Kurashiki Central Hospital between April 2016 and September 2020. Before the FROGS technique was implemented, 23 patients had already been admitted (before-FROGS group). After November 2019,14 patients were admitted, all of whom underwent FROGS as the first treatment choice (after-FROGS group). The demographic characteristics of all patients are summarized in Table 1. 
Table 1

Demographic characteristics of the 37 patients with obturator hernia

\begin{tabular}{|c|c|c|c|c|c|c|c|c|c|c|c|c|}
\hline $\begin{array}{l}\text { Patient } \\
\text { no. }\end{array}$ & FROGS & Age & BMI & $\begin{array}{l}\text { Symptom } \\
\text { duration } \\
\text { (days) }\end{array}$ & $\begin{array}{l}\text { Hospital } \\
\text { stay } \\
\text { (days) }\end{array}$ & $\begin{array}{l}\text { Prolapsed } \\
\text { bowel } \\
\text { diameter } \\
\text { (cm) }\end{array}$ & $\begin{array}{l}\text { Lesion } \\
\text { side }\end{array}$ & $\begin{array}{l}\text { Manual } \\
\text { reduction }\end{array}$ & $\begin{array}{l}\text { Emergency } \\
\text { surgery }\end{array}$ & $\begin{array}{l}\text { Operative } \\
\text { method }\end{array}$ & $\begin{array}{l}\text { Bowel } \\
\text { resection }\end{array}$ & Cardiopathy \\
\hline 1 & Before & 88 & 17.9 & 2 & 8 & 2.39 & Left & Not tried & $Y$ & TAPP & $Y$ & + \\
\hline 2 & Before & 87 & 17.1 & 0 & 6 & 2.14 & Right & Not tried & $Y$ & $\begin{array}{l}\text { Inguinal } \\
\text { approach }\end{array}$ & $\mathrm{N}$ & \\
\hline 3 & Before & 93 & 13.0 & 1 & 22 & 1.96 & Left & Not tried & Y & $\begin{array}{l}\text { Inguinal } \\
\text { approach }\end{array}$ & $\mathrm{N}$ & + \\
\hline 4 & Before & 87 & 17.1 & 2 & 5 & 2.26 & Left & Failure & Y & $\begin{array}{l}\text { Inguinal } \\
\text { approach }\end{array}$ & $N$ & \\
\hline 5 & Before & 92 & 19.8 & 1 & 5 & 2.15 & Right & Failure & $Y$ & $\begin{array}{l}\text { Inguinal } \\
\text { approach }\end{array}$ & $\mathrm{N}$ & \\
\hline 6 & Before & 84 & 17.3 & 1 & 9 & 2.61 & Right & Failure & Y & $\begin{array}{l}\text { Inguinal } \\
\text { approach }\end{array}$ & $\mathrm{N}$ & \\
\hline 7 & Before & 102 & 18.1 & 0 & 4 & 2.56 & Left & Failure & $Y$ & $\begin{array}{l}\text { Inguinal } \\
\text { approach }\end{array}$ & $\mathrm{N}$ & \\
\hline 8 & Before & 80 & 14.2 & 1 & 9 & 1.84 & Right & Not tried & Y & $\begin{array}{l}\text { Inguinal } \\
\text { approach }\end{array}$ & $\mathrm{N}$ & \\
\hline 9 & Before & 91 & 16.3 & 0 & 20 & 1.57 & Right & Not tried & Y & $\begin{array}{l}\text { Inguinal } \\
\text { approach }\end{array}$ & $\mathrm{N}$ & \\
\hline 10 & Before & 78 & 14.2 & 2 & 46 & 2.89 & Left & Failure & Y & $\begin{array}{l}\text { Inguinal } \\
\text { approach }\end{array}$ & $Y$ & \\
\hline 11 & Before & 96 & 18.5 & 3 & 6 & 3.41 & Right & Failure & Y & $\begin{array}{l}\text { Inguinal } \\
\text { approach }\end{array}$ & $Y$ & \\
\hline 12 & Before & 93 & 17.3 & 4 & 15 & 3.43 & Right & Not tried & $Y$ & $\begin{array}{l}\text { Inguinal } \\
\text { approach }\end{array}$ & $Y$ & + \\
\hline 13 & Before & 90 & 19.5 & 1 & 12 & 2.43 & Left & Failure & Y & $\begin{array}{l}\text { Inguinal } \\
\text { approach }\end{array}$ & $Y$ & + \\
\hline 14 & Before & 88 & 16.2 & 0 & 8 & 2.45 & Right & Not tried & Y & $\begin{array}{l}\text { Inguinal } \\
\text { approach }\end{array}$ & $\mathrm{N}$ & \\
\hline 15 & Before & 84 & 17.9 & 2 & 3 & 3.17 & Left & Success & $\mathrm{N}$ & TAPP & $\mathrm{N}$ & \\
\hline 16 & Before & 82 & 13.5 & 7 & 41 & 1.65 & Right & Failure & $Y$ & $\begin{array}{l}\text { Inguinal } \\
\text { approach }\end{array}$ & $\mathrm{Y}$ & \\
\hline 17 & Before & 88 & 16.0 & 1 & 2 & 2.3 & Right & Not tried & $Y$ & TAPP & $\mathrm{N}$ & + \\
\hline 18 & Before & 88 & 19.2 & 1 & 7 & 1.6 & Right & Failure & Y & Laparotomy & $\mathrm{Y}$ & + \\
\hline 19 & Before & 90 & 18.3 & 1 & 6 & 2.1 & Right & Failure & $\mathrm{N}$ & - & $\mathrm{N}$ & + \\
\hline 20 & Before & 92 & 18.7 & 3 & 27 & 2.11 & Left & Failure & $Y$ & $\begin{array}{l}\text { Inguinal } \\
\text { approach }\end{array}$ & $Y$ & + \\
\hline 21 & Before & 85 & 19.3 & 1 & 7 & 2.32 & Left & Failure & Y & TAPP & $\mathrm{N}$ & \\
\hline 22 & Before & 81 & 17.6 & 0 & 23 & 2.11 & Right & Not tried & $Y$ & TAPP & $\mathrm{N}$ & \\
\hline 23 & Before & 93 & 26.5 & 1 & 8 & 2.51 & Left & Failure & $Y$ & Laparotomy & $\mathrm{N}$ & \\
\hline 24 & After & 90 & 12.8 & 3 & 3 & 1.98 & Left & Success & $\mathrm{N}$ & TAPP & $\mathrm{N}$ & \\
\hline 25 & After & 97 & 17.4 & 2 & 11 & 2.81 & Right & Success & $\mathrm{N}$ & - & $\mathrm{N}$ & \\
\hline 26 & After & 82 & 16.3 & 0 & 2 & 2.85 & Left & Success & $\mathrm{N}$ & TAPP & $\mathrm{N}$ & \\
\hline 27 & After & 90 & 24.3 & 0 & 16 & 3.18 & Right & Success & $N$ & TAPP & $\mathrm{N}$ & + \\
\hline 28 & After & 91 & 14.2 & 2 & 4 & 2.57 & Left & Success & $\mathrm{N}$ & - & $\mathrm{N}$ & + \\
\hline 29 & After & 85 & 16.1 & 3 & 12 & 2.64 & Right & Success & $\mathrm{N}$ & - & $\mathrm{N}$ & \\
\hline 30 & After & 98 & 17.3 & 0 & 7 & 3.17 & Right & Success & $\mathrm{N}$ & TAPP & $\mathrm{N}$ & \\
\hline 31 & After & 76 & 13.0 & 3 & 7 & 1.64 & Right & Success & $\mathrm{N}$ & - & $\mathrm{N}$ & \\
\hline 32 & After & 76 & 13.0 & 3 & 7 & 1.54 & Left & Success & $\mathrm{N}$ & - & $\mathrm{N}$ & \\
\hline 33 & After & 92 & 19.6 & 0 & 3 & 3.24 & Left & Success & $\mathrm{N}$ & - & $\mathrm{N}$ & + \\
\hline
\end{tabular}




\begin{tabular}{|llllllllllll}
\hline $\begin{array}{l}\text { Patient } \\
\text { no. }\end{array}$ & FROGS & Age & BMI & $\begin{array}{l}\text { Symptom } \\
\text { duration } \\
\text { (days) }\end{array}$ & $\begin{array}{l}\text { Hospital } \\
\text { stay } \\
\text { (days) }\end{array}$ & $\begin{array}{l}\text { Prolapsed } \\
\text { bowel } \\
\text { diameter } \\
\text { (cm) }\end{array}$ & $\begin{array}{l}\text { Lesion } \\
\text { side }\end{array}$ & $\begin{array}{l}\text { Manual } \\
\text { reduction }\end{array}$ & $\begin{array}{l}\text { Emergency } \\
\text { surgery }\end{array}$ & $\begin{array}{l}\text { Operative } \\
\text { method }\end{array}$ & $\begin{array}{l}\text { Bowel } \\
\text { resection }\end{array}$ \\
\hline 34 & After & 92 & 14.2 & 0 & 6 & 2.61 & Left & Success & $\mathrm{N}$ & - \\
\hline 35 & After & 82 & 13.1 & 0 & 3 & 3.03 & Left & Success & $\mathrm{N}$ & - & $\mathrm{N}$ \\
\hline 36 & After & 82 & 15.4 & 0 & 4 & 2.75 & Left & Success & $\mathrm{N}$ & TAPP & $\mathrm{N}$ \\
\hline 37 & After & 91 & 17.3 & 1 & 6 & 2.47 & Right & Success & $\mathrm{N}$ & TAPP & N \\
\hline
\end{tabular}

All the 37 patients were women and received a preoperative diagnosis.

$B M /$ body mass index, CKD chronic kidney disease, DM diabetes mellitus, FROGSFour-hand Reduction for Obturator hernia with the Guidance of Sonography,

All patients were females. All 37 patients were diagnosed with obturator hernia preoperatively by computed tomography. There were no significant differences in age, lesion side, duration of symptoms, diameter of the prolapsed bowel, and predisposing factors between the two groups. Body mass index was significantly lower in the after-FROGS group than in the before-FROGS group $(p=0.0158$, Table 2$)$.

Table 2

Patient characteristics at the first visit compared between the two groups

\begin{tabular}{|llll|}
\hline & before-FROGS & after-FROGS & p-value \\
\hline Age & $88.3 \pm 5.53$ & $87.4 \pm 7.01$ & 0.660 \\
\hline Body mass index & $17.5 \pm 2.73$ & $16.0 \pm 3.17$ & 0.016 \\
\hline Symptom duration (days) & $1.52 \pm 1.59$ & $1.21 \pm 1.37$ & 0.541 \\
\hline Prolapsed bowel diameter (cm) & $2.35 \pm 0.51$ & $2.61 \pm 0.54$ & 0.152 \\
\hline Lesion side (right/left) & $13 / 10$ & $6 / 8$ & 0.420 \\
\hline Predisposing factors & & & \\
\hline Cardiopathy & $8(34.8)$ & $4(28.6)$ & 1.000 \\
\hline Vascular disease & $5(21.7)$ & $3(21.4)$ & 1.000 \\
\hline Hypertension & $9(39.1)$ & $5(35.7)$ & 1.000 \\
\hline Lung disease & $3(13.0)$ & $0(0)$ & 0.275 \\
\hline Diabetes mellitus & $1(4.3)$ & $1(7.1)$ & 1.000 \\
\hline Chronic kidney disease & $4(17.4)$ & $0(0)$ & 0.276 \\
\hline Dementia & $1(4.3)$ & $2(14.3)$ & 0.544 \\
\hline Manual reduction (success/failure) & $14 / 14(100)$ & $1 / 14(7.14)$ & $<0.001$ \\
\hline Patients undergoing emergency surgery & $0(0)$ & $21(91.3)$ & $<0.001$ \\
\hline Value are expressed as mean \pm SD or frequency (\%). & & \\
\hline FROGSFour-hand Reduction for Obturator hernia with the Guidance of Sonography & \\
\hline
\end{tabular}

Table 3. Operative method compared between elective and emergency surgery

$\begin{array}{llll} & \text { elective surgery } & \text { emergency surgery } & p \text {-value } \\ \text { TAPP/inguinal approach or laparotomy } & 15 / 0 & 4 / 17 & <0.001\end{array}$

TAPP transabdominal preperitoneal repair

All 15 elective surgeries in both groups were performed using laparoscopic repair (transabdominal preperitoneal, TAPP). On the other hand, out of 21 patients who underwent emergency surgeries, only 4 (19.0\%) underwent laparoscopic repair (TAPP). The rate of TAPP was significantly higher in patients who underwent elective surgery $(p<0.001$, Table 3$)$.

Manual reduction was successfully performed in all 14 patients in the after-FROGS group (success rate of $100 \%$ ). In the before-FROGS group, 14 patients underwent manual reduction, out of whom only one was successfully treated (success rate of 7.14\%) using the non-FROGS method. The success rate of manual reduction was significantly higher in the after-FROGS group than in the before-FROGS group $(p<0.001$, Table 2). 
Of the 14 patients in the after-FROGS group, six underwent elective surgery. All six operations were performed using TAPP. Eight patients did not undergo elective surgery because of comorbidities. In the before-FROGS group, successful manual reduction was performed in only one patient who underwent elective surgery that was performed using TAPP repair. Emergency surgery could not be performed on one patient because of severe heart failure; this patient died at 6 days after admission. The other 21 patients underwent emergency surgery, including 17 patients who underwent laparotomy and 4 patients who underwent TAPP. The number of patients who underwent emergency surgery was significantly smaller in the after-FROGS group than in the before-FROGS group ( $p<$ 0.001 , Table 2).

Bowel resection was avoided in all 14 patients in the after-FROGS group, whereas 8 patients underwent bowel resection in the before-FROGS group. The bowel resection rate was significantly lower in the after-FROGS group than in the before-FROGS group $(p=0.015$, Table 4$)$. There were no significant differences in postoperative complication and mortality rates within 30 days after hernia presentation between the two groups.

Table 4

Operative and postoperative data compared between the two groups

\begin{tabular}{|llll|}
\hline & before-FROGS & after-FROGS & p-value \\
\hline Bowel resection & $8(34.8)$ & $0(0)$ & 0.015 \\
\hline Postoperative complications & $7(30.4)$ & $1(7.14)$ & 0.123 \\
\hline Death within 30 days after admission & $2(9.5)$ & $0(0)$ & 0.517 \\
\hline Value are expressed as frequency (\%). & & \\
\hline
\end{tabular}

\section{Discussion}

We statistically evaluated the effectiveness of FROGS as a new treatment strategy for obturator hernia. The successful rate of manual reduction of FROGS was $100 \%$ so far. The result showed that patients can avoid emergency surgery and bowel reduction without increasing postprocedural complications and mortality within 30 days after hernia presentation thanks to FROGS.

Obturator hernia is a rare type of abdominal hernia. Its pathogenesis is attributed to the loss of preperitoneal fat and lymphatic tissues, which normally overlie the obturator canal, thus creating a space around obturator vessels and nerves [12]. Concomitant illnesses, such as chronic obstructive pulmonary disease, constipation, and kyphoscoliosis, could result in increased intraperitoneal pressure and facilitate the growth of the hernial sac [13]. Lean and elderly women are usually affected as they have less preperitoneal fat and several comorbidities that favor the pathogenesis of this condition.

Laparotomy use to be the standard approach for the treatment of obturator hernia since preoperative diagnosis is difficult owing to its rarity and non-specific signs and symptoms. Ziegler et al. mentioned that "An obturator hernia needs a laparotomy, not a diagnosis" [14]. Likewise, many surgeons believe that emergency laparotomy is the most optimal treatment for possible incarcerated obturator hernias. However, recent advances in imaging techniques, such as computed tomography and ultrasonography, have improved the rate of correct preoperative diagnosis, and this has made less invasive approaches feasible to undertake [2-4]. A few studies have described less invasive therapeutic strategies, such as elective surgeries following successful manual reduction [5-7]. It was shown that elective surgeries are associated with a higher rate of TAPP implementation. The reason for undertaking laparoscopic approaches less frequently in emergency surgeries could be attributed to the smaller peritoneal cavity resulting from a dilated intestine.

This study aimed to evaluate the efficacy of FROGS as the first choice of treatment for incarcerated obturator hernias. Usually, patients with obturator hernia have comorbidities, and this makes them unsuitable for emergency surgeries. They should be treated with less invasive therapy in an elective setting, if possible. In addition, it is often the case that some patients and their families do not consent to surgery. Ceresoli et al., showed that emergency surgery for complicated inguinal hernias is burdened by high morbidity and mortality rates in elderly patients [15]. For patients with asymptomatic or minimally symptomatic inguinal hernias, watchful waiting is recognized as an acceptable option [16,17]. Although these studies have mainly focused on inguinal hernias, the results could apply to obturator hernias as well.

In our study, emergency surgeries were avoided in asymptomatic or minimally symptomatic patients because of the implementation of FROGS. Some of these patients underwent safe elective TAPP repair, while in others, comorbidities or family wishes were decisive factors. Irrespective of whether elective surgery was performed or not, bowel resection was avoided in all patients. In addition, the short-term prognosis between the after-FROGS and before-FROGS groups was comparable. Although the balance between the risks of elective surgery and the risks of a watchful approach is still a topic of debate in the absence of specific recommendations for elderly patients [15], a watchful approach could be a choice based on this result and the literature.

Although patients who do not undergo elective surgery are still at risk of recurrence, FROGS can be reproducible in cases of recurrence owing to its high success rate. Therefore, we believe that FROGS can be the first choice of treatment in any case of obturator hernia incarceration. The mechanism of FROGS is unclear and may be complex. We believe that complex coordinated movements of muscles around the obturator canal may play an important role. The driving pressure generated by these movements helps surgeons to reduce the hernial sac. In addition, at some point during this maneuver, the obturator canal may be maximally relaxed (usually in Step 3, based on our experience), and by repeating FROGS, we can eventually find this particular point.

The necessity of bowel resection is hard to decide, especially if FROGS is implemented. No patients in the after-FROGS group required bowel resection. The longest duration from symptom onset to hernia presentation was 72 hours. Based on this result, we can argue that if there are no obvious evidence of strangulation or ischemia, manual reduction using FROGS is acceptable within 72 hours.

Page $6 / 10$ 
The limitation of this study is the relatively small sample size. Further observations and analyses are necessary to confirm the effectiveness of FROGS. Notwithstanding these limitations, manual reduction with FROGS was found to be safe and reproducible and can be the first treatment choice for patients with obturator hernias. FROGS can be used instead of emergency surgery as a less invasive method to treat patients with obturator hernias while preserving the bowel.

\section{Conclusion}

Based on retrospective data of 37 patients, which include 14 patients who underwent FROGS (after-FROGS group) and 23 patients who did not (before-FROGS group), FROGS was found to be safe and reproducible and can be the first treatment choice for obturator hernia, instead of emergency surgery. More observations and analyses are necessary to further discuss the scope of the indication of FROGS since the sample size is relatively small. However, we believe this result is quite promising.

\section{Abbreviations}

FROGS: Four-hand Reduction for Obturator hernia with the Guidance of Sonography

TAPP repair: transabdominal preperitoneal repair

BMI: body mass index

DM: diabetes mellitus,

CKD: chronic kidney disease

\section{Declarations}

\section{Funding}

No funding was obtained for this study.

\section{Ethics approval}

This study was approved by the Kurashiki Central Hospital Ethics Committee (the committee's reference number : 3497). All procedures performed in this study that involved human participants were in accordance with the ethical standards of the institutional and/or national research committee and with the 1964 Helsinki Declaration and its later amendments or comparable ethical standards.

\section{Consent for publication}

Written informed consent was obtained for the academic use of patients' photographs.

\section{Availability of data and material}

Not applicable.

\section{Competing interest}

YT, KK, YN, and KK declare that they have no conflict of interest.

\section{Authors' contributions}

All authors contributed to the study conception and design. YT and KK performed material preparation, data collection, and data analysis. YT wrote the first draft of the manuscript, and all authors commented on previous versions of the manuscript. All authors read and approved the final manuscript.

\section{References}

1. Schizas D, Apostolou K, Hasemaki N, Kanavidis P, Tsapralis D, Garmpis N, et al. Obturator hernias: a systematic review of the literature. Hernia. 2021;25:193-204.

2. Kammori M, Mafune K, Hirashima T, Kawahara M, Hashimoto M, Ogawa T, et al. Forty-three cases of obturator hernia. Am J Surg. 2004;187:549-52.

3. ljiri R, Kanamaru H, Yokoyama H, Shirakawa M, Hashimoto H, Yoshino G. Obturator hernia: the usefulness of computed tomography in diagnosis. Surgery. 1996;119:137-40.

4. Bergstein JM, Condon RE. Obturator hernia: current diagnosis and treatment. Surgery. 1996;119:133-6.

5. Yokoyama Y, Yamaguchi A, Isogai M, Hori A, Kaneoka Y. Thirty-six cases of obturator hernia: does computed tomography contribute to postoperative outcome? World J Surg. 1999;23:214-7.

6. Mantoo SK, Mak K, Tan TJ. Obturator hernia: diagnosis and treatment in the modern era. Singapore Med J. 2009;50:866-70.

7. Igari K, Ochiai T, Aihira A, Kumagai Y, lida M, Yamazaki S. Clinical presentation of obturator hernia and review of the literature. Hernia. 2010;14:409-13. 
8. Funato T, Ichihashi M, Inui H, Tarao M, Goto A. A case report of elective operation following noninvasive reduction of obturator hernia (in Japanese with English abstract). Jpn J Gastroenterol Surg. 1990;23:810-4.

9. Yamamoto H, Kato S, Hida K, Shimizu K, Konishi Y, Takeda J. Two cases of obturator hernia performed an elective surgery via inguinal method after manual repositioning (in Japanese with English abstract). J Jpn Surg Assoc. 2005;66:1485-8.

10. Tanaka N, Kikuchi J, Ando T. Elective plug repair of an incarcerated obturator hernia by thigh approach after noninvasive manual reduction: report of two cases. Surg Today. 2010;40:181-4.

11. Shigemitsu Y, Akagi T, Morimoto A, Ishio T, Shiraishi N, Kitano S. The maneuver to release an incarcerated obturator hernia. Hernia. 2012;16:715-7.

12. Chang SS, Shan YS, Lin YJ, Tai YS, Lin PW. A review of obturator hernia and a proposed algorithm for its diagnosis and treatment. World J Surg. 2005;29:450-4.

13. Cai X, Song X, Cai X. Strangulated intestinal obstruction secondary to a typical obturator hernia: a case report with literature review. Int J Med Sci. 2012;9:213-5.

14. Ziegler DW, Rhoads JE Jr. Obturator hernia needs a laparotomy, not a diagnosis. Am J Surg. 1995;170:67-8.

15. Ceresoli M, Carissimi F, Nigro A, Fransvea P, Lepre L, Braga M, et al. Emergency hernia repair in the elderly: multivariate analysis of morbidity and mortality from an Italian registry. Hernia. 2020.

16. Fitzgibbons RJ Jr, Giobbie-Hurder A, Gibbs JO, Dunlop DD, Reda DJ, McCarthy M, et al. Watchful waiting vs repair of inguinal hernia in minimally symptomatic men: a randomized clinical trial. JAMA. 2006;295:285-92.

17. O’Dwyer PJ, Chung L. Watchful waiting was as safe as surgical repair for minimally symptomatic inguinal hernias. Evid Based Med. $2006 ; 11: 73$.

\section{Figures}

$$
\text { Fig.1 }
$$

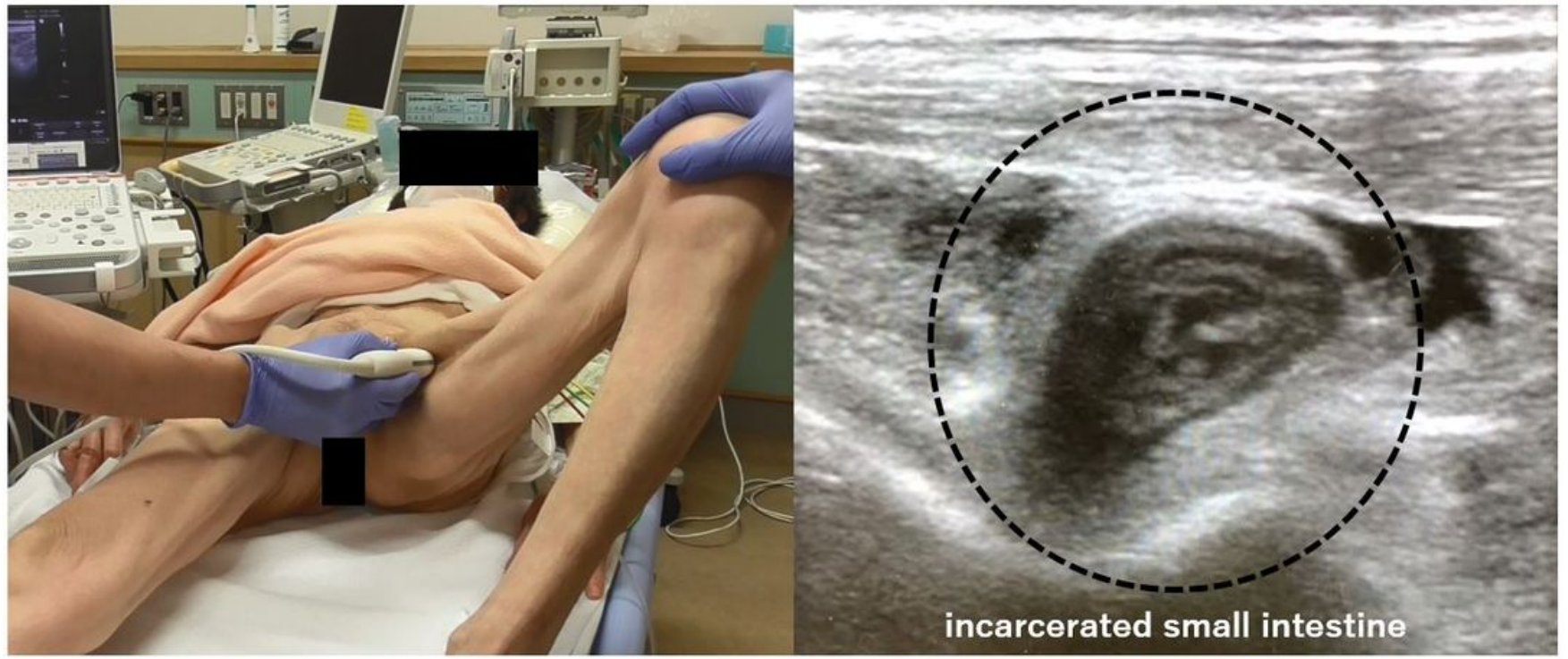

\section{Figure 1}

A surgeon standing on the right side of the patients confirms the hernial sac between the adductor longus and the pubis while an assistant standing on the left side of the patient pulls the leg and gently distract the hip joint to allow ultrasonography of the hernial sac (left panel). An ultrasound image showing a dilated small intestine incarcerated in the hernial sac (right panel). 


\section{Fig.2}

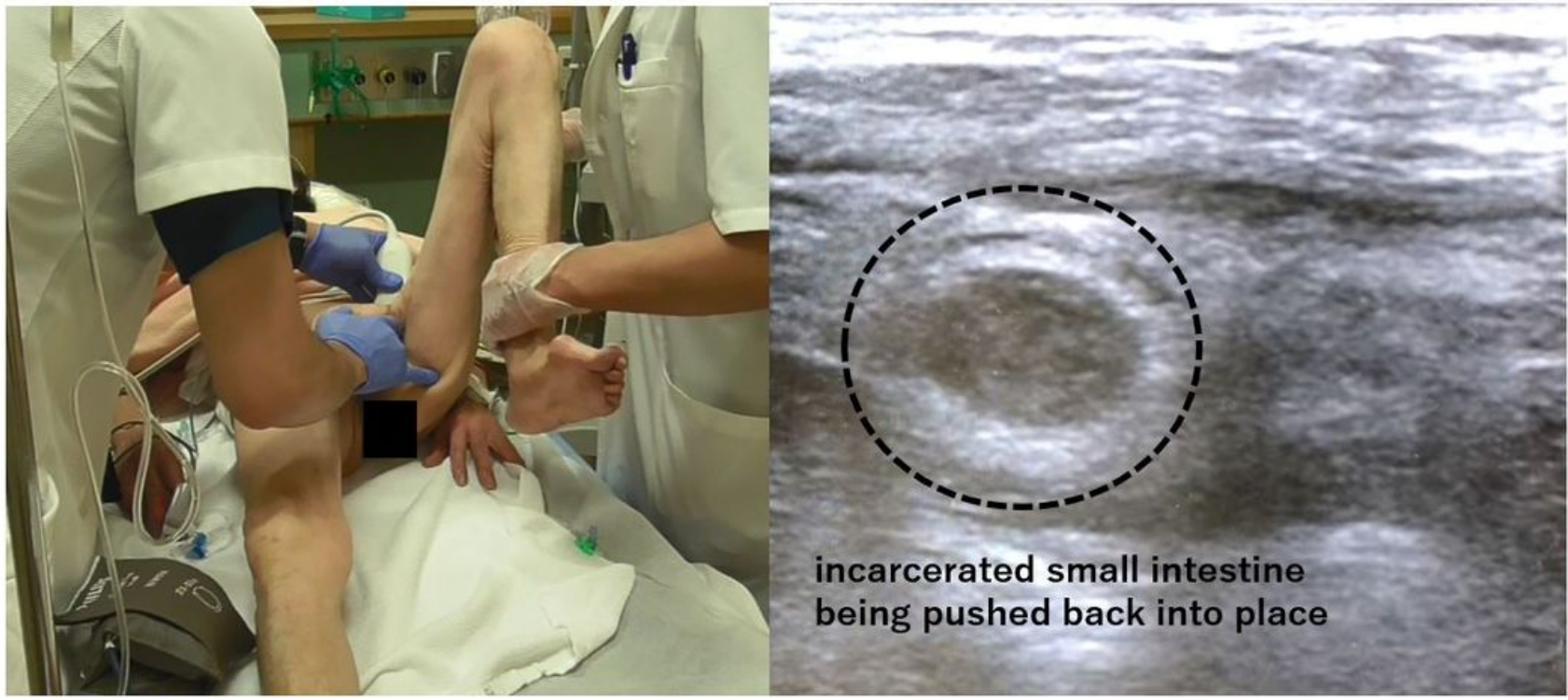

\section{Figure 2}

STEP 1 and STEP 2. The surgeon places the transducer on the patient's groin (just above the inguinal ligament) with the left hand and pushes the hernial sac with the right hand. Meanwhile, the assistant flexes the hip and knee joints and produces slight lateral rotation of the hip joint to widen the hernia orifice (left panel). An ultrasound image showing the incarcerated small intestine manually pushed back into place with the surgeon's right hand (right panel).

\section{Fig.3}

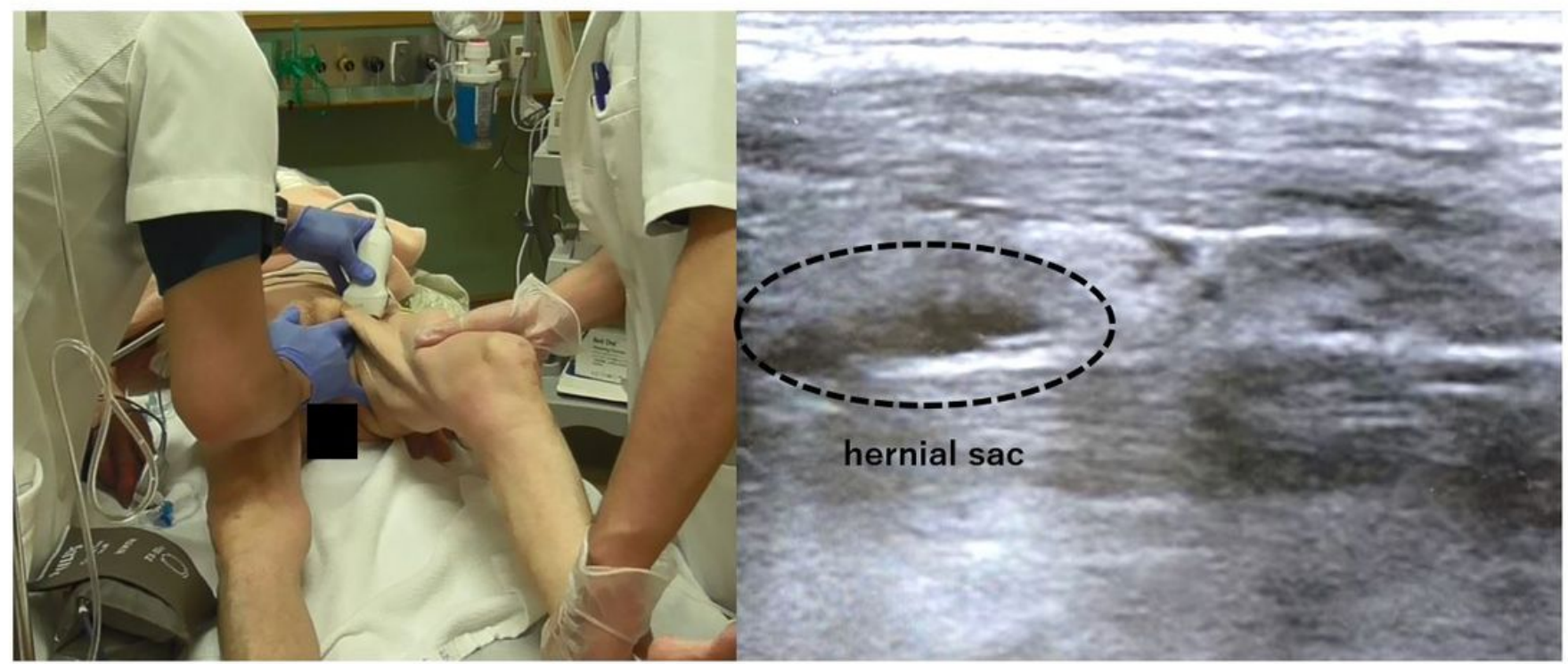

Figure 3 
STEP 3. While the assistant extends the leg, the surgeon pushes the hernial sac even harder (left panel). An ultrasound image showing the empty hernial sac after this maneuver (right panel). 